\title{
Anastomotic Stricture after Esophageal Atresia Repair: A Critical Review of Recent Literature
}

\author{
Robert Baird $^{1}$ Jean-Martin Laberge ${ }^{1}$ Dominique Lévesque ${ }^{2}$ \\ ${ }^{1}$ Division of Pediatric General and Thoracic Surgery, Montreal \\ Children's Hospital, McGill University Health Center, Montreal, \\ Quebec, Canada

\begin{abstract}
Address for correspondence Robert Baird, MSC, MDCM, FRCSC, Montreal Children's Hospital, 2300 Tupper Street, Room C-812, Montreal, Quebec, Canada H3H 1P3 (e-mail: robert.baird@mail.mcgill.ca).
\end{abstract}

2 Division of Pediatric Gastroenterology, Montreal Children's Hospital, McGill University Health Center, Montreal, Quebec, Canada

Eur J Pediatr Surg 2013;23:204-213.

\begin{abstract}
Keywords

- esophageal atresia

- anastomotic stricture

- esophageal stenting

- mitomycin C

- steroid injection

Anastomotic strictures (ASs) complicate the postoperative course of roughly onethird of all patients with esophageal atresia with or without tracheoesophageal fistula. Its development is multifactorial, but is due in part to tension on the anastomosis, gastroesophageal reflux disease, and the presence of a leak in the early postoperative period. Efforts at reducing the rate of AS have been largely unsuccessful, although meticulous technique and aggressive acid suppression remain the cornerstones of perioperative care. Once an AS has been confirmed, the first-line treatment remains a course of esophageal dilatation. Adjuncts to dilatation are frequently required, including steroid injection or the topical application of mitomycin C. Currently, there is insufficient evidence to promote one at the expense of the other. Esophageal stenting has recently been added to the algorithm of treatment, although additional literature is required to confirm its safety and efficacy. Finally, stricture resection followed by primary esophageal anastomosis or, rarely, esophageal replacement with an interposition graft remain options for AS refractory to all other forms of treatment.
\end{abstract}

\section{Introduction}

Esophageal atresia (EA) with or without tracheoesophageal fistula (TEF) remains one of the most common surgically correctable gastrointestinal malformations, and has demonstrated improving survival rates since the original description of repair and primary anastomosis in 1943 by Haight. ${ }^{1}$ However, anastomotic strictures (ASs) continue to complicate the long-term management of these patients, and publications evaluating long-term outcomes demonstrate no significant improvement over time. ${ }^{2-4}$ This review will evaluate the recent literature surrounding AS, including its definition and incidence, as well as the various medical and surgical preventive and treatment strategies in existence.

received

May 2, 2013

accepted

May 2, 2013

published online

May 29, 2013

\section{Epidemiology and Definition of Anastomotic Stricture}

\section{Definition}

An AS after EA repair is generally defined as a narrowing that results in symptoms or signs such as dysphagia, regurgitation, oxygen desaturation during feeding, aspiration, and failure to thrive. However, several distinct complications may lead to similar symptoms in EA patients, including esophageal dysmotility, recurrent TEF, gastroesophageal reflux disease (GERD), tracheomalacia, laryngeal clefts, and vocal cord dysfunction. ${ }^{5-8}$ The clinician must therefore evaluate the degree of narrowing seen on fluoroscopy or endoscopy in the context of each of the other possible complications, many of which may be simultaneously present. Importantly, the

(c) 2013 Georg Thieme Verlag KG Stuttgart · New York
DOI http://dx.doi.org/ $10.1055 / \mathrm{s}-0033-1347917$. ISSN 0939-7248. 
Table 1 Definition of refractory and recurrent esophageal stricture

\begin{tabular}{|c|c|c|}
\hline & Adult definition $^{10}$ & Proposed pediatric definition \\
\hline Refractory & $\begin{array}{l}\text { Inability to dilate to } 14 \mathrm{~mm} \text { diameter over five sessions at } \\
\text { 2-week interval }\end{array}$ & SI remains $>10 \%$ after five sessions \\
\hline Recurrent & $\begin{array}{l}\text { Inability to maintain a satisfactory diameter }>4 \text { weeks once } \\
14 \mathrm{~mm} \text { reached }\end{array}$ & $\begin{array}{l}\text { Recurrence of symptoms or } \mathrm{SI}>50 \% \text { after }> \\
4 \text { weeks after } \mathrm{SI}<10 \% \text { achieved }\end{array}$ \\
\hline
\end{tabular}

Note: SI, stricture index, defined by Said et $\mathrm{al}^{13}$ as $(D-d) / D \times 100$, where $D$ is the diameter of esophagus below the stricture and $d$ the diameter of the stricture.

initial anastomotic narrowing seen on postoperative contrast esophagram does not correlate with the development of a symptomatic $\mathrm{AS}^{9}$; therefore, one must wait for the development of symptoms and have a low threshold for repeating an esophagram.

A symptomatic stricture may respond to a single dilatation, or may become refractory or recurrent. Kochman et al ${ }^{10}$ have proposed a definition for these two entities, which has been adopted by others, ${ }^{11,12}$ but it currently applies to adults. - Table 1 represents an attempt at translating the adult definition to the pediatric context. Said et al described the anastomotic stricture index (SI) to quantify the severity of the stricture and monitor its subsequent response to treatment. ${ }^{13}$ The SI is defined as: $\mathrm{SI}=(D-d) / D \times 100$, where $D$ is the diameter of esophagus below the stricture and $d$ is the diameter of the stricture. All their patients were symptomatic and had a SI > 50\% before dilatations were initiated. Nambirajan et al described an "anastomotic index" using the ratio of maximum upper pouch diameter to that of the anastomosis on contrast study. ${ }^{9}$ More recently, Parolini et al also used the upper pouch diameter in relation to the stricture diameter, based on endoscopic assessment, yet they called this the SI and quoted Said et al. ${ }^{14}$ None of these calculations have been widely used in a standardized fashion, but it would seem that using the distal esophageal diameter on contrast study more accurately reflects the true esophageal diameter (i.e., using the SI as originally described). ${ }^{13,15}$

\section{Incidence}

-Table 2 provides a summary of case series reporting stricture rates in survivors after open EA repair, with no appreciable improvement in the stricture rate over time. Most of these studies used the need for dilatation as a sine qua non of the diagnosis, with approximately $40 \%$ occurrence overall. A recent comparative review of open and thoracoscopic EA repairs demonstrated an optimistic $9 \%$ stricture rate for the minimally invasive approach, ${ }^{16}$ although more contemporary series have documented stricture rates that approach the open rate ( - Table 3). A systematic review comparing open to thoracoscopic repair also demonstrated a wide variation in AS, from 9 to $45 \%$ after thoracoscopy (defining AS as requiring $>1$ dilatation) and from 4.3 to $60 \%$ after thoracotomy (variable definition of AS) ${ }^{17}$; the author concluded that the incidence of AS was comparable between the two approaches and that a clear definition of AS would be important.

\section{Prevention}

Although an ounce of prevention is worth a pound of cure, numerous attempts at describing modifications to the technique of anastomosis have failed to demonstrate a durable solution to the development of AS. The end-to-side anastomosis that was used for much of the 1970s to 1980s by some surgeons may have reduced the stricture rate when compared with the end-to-end technique, ${ }^{18,19}$ but was shown to be associated with an increase in the refistulization and overall

Table 2 Summary of existing literature from 1990 to present evaluating the incidence of anastomotic stricture after open esophageal atresia repair

\begin{tabular}{|l|l|l|l|}
\hline Study, year & Subjects, no. of type C & Stricture rate & Definition of stricture \\
\hline Chittmittrapap et al $1990^{23}$ & $N=184$ (not reported) & $37 \%(74)$ & Required dilatation \\
\hline Poenaru et al $1991^{20}$ & $N=74(74)$ & $24 \%(18)$ & Required dilatation \\
\hline Engum et al $1995^{2}$ & $N=215(178)$ & $35 \%(75)$ & Required dilatation \\
\hline Konkin et al $2003^{116}$ & $N=136(119)$ & $52 \%(69)$ & Not stated \\
\hline Laín et al $2007^{74}$ & $N=34(29)$ & $79 \%(27)$ & Required dilatation \\
\hline Serhal et al $2010^{59}$ & $N=64(64)$ & $37 \%(23)$ & Contrast esophagram \\
\hline Alshehri et al $2012^{3}$ & $N=50(39)$ & $36 \%(18)$ & Required dilatation \\
\hline Koivusalo et al $2013^{4}$ & $N=127(110)$ & $78 \%(102)$ & Based on endoscopy \\
\hline Total & & $38 \%>5$ dilatations & \\
\hline
\end{tabular}


Table 3 Summary of existing literature evaluating the incidence of anastomotic stricture after thoracoscopic esophageal atresia repair

\begin{tabular}{|l|l|l|l|}
\hline Study, year & Subjects, no. of type C & Stricture rate & Definition of stricture \\
\hline Holcomb et al $2005^{43}$ & $N=104(104)$ & $\begin{array}{l}32 \%(33) \\
3.8 \%>4 \text { dilatations }\end{array}$ & Required dilatation \\
\hline Borruto et al $2012^{16, a}$ & $N=69(69)$ & $9 \%(6)$ & Dependent on individual studies \\
\hline Rothenberg $2012^{117}$ & $N=49(43)$ & $30 \%(15)$ & Required dilatation \\
\hline Huang et al $2012^{118}$ & $N=31(31)$ & $23 \%(7)$ & Required dilatation \\
\hline
\end{tabular}

${ }^{a}$ Composite of four individual studies.

mortality rate. ${ }^{20} \mathrm{~A}$ two-layer anastomosis has been found to be inferior to a single-layer closure several decades ago. ${ }^{21,22}$ The suture material used to create the anastomosis has also been investigated; although older studies have confirmed a higher complication rate (including stricture) with silk, ${ }^{23,24} \mathrm{a}$ more recent investigation demonstrated no difference between monofilament and braided sutures, or between resorbable and nonresorbable sutures. ${ }^{25}$ Although the numbers were too small to draw any definitive conclusions (99 patients, five types of suture material), silk had the lowest stricture rate in that study (30 vs. $42 \%$ overall).

Although newer variants of the anastomotic technique continues to be described, ${ }^{26,27}$ the overarching limitation of the anastomosis continues to be the inherent tension between the upper and lower pouches. This has been shown to predict the development of GER in an animal model, a significant risk factor for the development of stricture. ${ }^{28}$ Although several studies have attempted to address the practical quantification of anastomotic tension in vivo, ${ }^{29,30}$ there is general consensus that the longer the gap length, the higher the tension placed on the primary anastomosis, resulting in GER and ischemia, and consequently, the higher the risk of developing an AS. Multiple studies have linked gap length to anastomotic leak, stricture, and GER, ${ }^{23,31-33}$ with a recent study proposing precise intraoperative measurement using calipers before division of the TEF and upper pouch mobilization; the authors present a new prognostic classification based on gap length, ${ }^{34}$ a concept already proposed in the 1990 s. $^{35}$

Acid suppression is an imperative component of the perioperative care of patients after EA repair to minimize the contact between the healing anastomosis and the acidity of GER, ${ }^{36}$ although a recent review of EA management in the United Kingdom and Ireland revealed that only $51 \%$ of patients were prescribed acid suppression medication in the neonatal period. ${ }^{37}$ Initial prophylaxis with $\mathrm{H} 2$ blockers is generally used, but in high-risk patients or those with an established stricture, proton pump inhibitors (PPIs) become the prophylaxis of choice and have been demonstrated to improve stricture healing independent of other treatment modalities. ${ }^{38}$ On the contrary, recent evidence confirms that PPIs alone do not necessarily prevent stricture formation. ${ }^{39}$ The optimal duration of antireflux treatment is unclear; documented reflux complicates at least $50 \%$ of EA patients and rarely improves over time. ${ }^{40}$ The role of fundoplication in the treatment algorithm after EA repair remains controversial and is addressed in detail elsewhere. In a series from Ann Arbor, 26\% of 80 patients underwent fundoplication for GERD refractory to medical treatment. Although the majority of these patients ultimately had a favorable outcome, complications after surgery were frequent and three patients died as a direct consequence of antireflux surgery. ${ }^{41}$ More recent series, both open and thoracoscopic, continue to support the use of fundoplication in $\mathrm{pH}$ proven GER, ${ }^{4,42,43}$ although controversy remains about whether a complete or a partial fundoplication is most appropriate for EA patients. ${ }^{44-46}$

The development of AS after EA repair continues to be a vexing complication. End-to-end repair with minimal tension appears protective. Aggressive treatment of GERD is critical in minimizing stricture formation, including medical therapy and antireflux surgery if supported by evidence of uncontrolled reflux.

\section{Treatment}

\section{Dilatation}

Esophageal dilatation has been a well-established treatment modality for benign strictures in adults for more than 50 years. ${ }^{47,48}$ After the establishment of bougies or balloons in the treatment of peptic strictures in adults, their use in children soon followed. ${ }^{49,50}$ In general, strictures are characterized as simple (focal, straight, large diameter) or complex (long segment, i.e., $>2 \mathrm{~cm}$, tortuous). Strictures secondary to caustic ingestion are typically complex in nature and challenging to treat while strictures secondary to EA nearly always result in a simple narrowing directly at the anastomotic site. ${ }^{51}$

The first dilatation for a repaired EA occurred 17 months after the first documented surgical repair by Haight, after which time the patient improved. ${ }^{52}$ Since then, encouraging case reports resulted in some centers incorporating dilatation into the routine postoperative management of EA patients. ${ }^{53,54}$ Although bougies were the first tools widely available to dilate esophageal strictures, balloon dilatation is now thought to be safer and more effective. The exception may be in patients with long or tortuous strictures (e.g., after caustic injuries) or very fibrotic strictures (e. g., after esophageal replacement), which is rarely the case for AS post-EA repair. ${ }^{13,55,56}$

\section{Bougie}

Three main types of bougies exist: tapered (Maloney) or blunt-tipped (Hunt) dilators inserted blindly, wire-guided 
bougies (Savary-Gilliard), and string-guided dilators (Tucker). ${ }^{12,57}$ The group from Lille has reported twice their experience with bougienage for treating AS after EA repair. In 2001, 20 patients had undergone bougienage, with 2 ultimately failing dilatation and 1 patient perforating and dying as a consequence. ${ }^{58}$ In a subsequent group of patients reported in 2010 , they demonstrated an $87 \%$ success rate with serial dilatations using the same Savary-Gilliard bougies in 23 patients, requiring a mean of 3.2 dilatations per child. No complications were reported. ${ }^{59}$ Other groups in Europe and other parts of the world continue to report good results with the same type of bougies. These are passed over a guidewire, which is introduced beyond the stricture by endoscopy or under fluoroscopy (or both); fluoroscopic guidance may also be used during dilatation. ${ }^{33,60-62}$ Maloney bougies (mercury or tungsten weighted) are now seldom used since their blind passage may lead to more perforations, especially in long complex strictures. ${ }^{63,64}$ Tucker dilators, which can be pulled in a retrograde fashion using a string, may be useful in patients who do not tolerate repeated general anesthesia, have a gastrostomy, and need frequent dilatations. ${ }^{65}$ The procedure can be performed at the bedside or as an outpatient under sedation.

\section{Balloon}

Successful balloon dilatation for esophageal stricturing in children was first reported in $1984 .{ }^{66}$ Balloon dilatations may be done under fluoroscopic guidance in the radiology suite under sedation or general anesthesia, or under endoscopic guidance in the operating room using general anesthesia, with or without fluoroscopy as an adjunct. Dr. Folkman's group in Boston reported the first series of balloon dilatations as an alternative to bougienage for the treatment of AS after EA repair, demonstrating 66\% resolution of symptoms with acceptable morbidity in nine patients. ${ }^{67}$ Other groups followed, including Said et al who reported a series of 25 patients with AS who were all managed with balloon dilatations under fluoroscopic guidance. After a mean of four sessions, $100 \%$ of patients achieved resolution of the stricture, albeit with two patients suffering esophageal perforations. ${ }^{13}$ Ko et al reported similar success using fluoroscopic balloon dilatation in 29 children, with three documented perforations. ${ }^{68}$ Over a 10-year period, Antoniou et al managed 59 patients using endoscopic balloon dilatation for the treat- ment of AS, with $80 \%$ of patients achieving a favorable outcome. Five patients required salvage (four had surgery and one was treated with a stent), and no perforations were reported. ${ }^{69}$ The maximal balloon inflation pressure used is either not reported or highly variable, from manual injection without measurement to $10 \mathrm{~atm}$ with the use of specially designed inflation systems ( - Table 4). A previous report has identified that esophageal rupture would occur at 280 pounds per square inch $(19 \mathrm{~atm}),{ }^{70}$ with a decreased margin of safety in a fibrotic stricture and presumably in younger children. Duration of inflation is also variable, most authors using 1 minute, then deflating and reinflating up to three times in the same session, and progressing by a maximum of two balloon sizes ( 2 to $3 \mathrm{~mm}$ total) at a time.

Some groups compared the two techniques (bougienage and balloon), and concluded that balloon reduced the number of dilatations required, increased success rate and decreased complications, however, the difference in complication rates were not statistically significant. ${ }^{55,56}$ On the contrary, others have reported equally good results with Savary-Gilliard bougies and balloon dilatation, although many of these reports are comprised primarily of patients with caustic injuries. ${ }^{71}$ Comparison between series is difficult, given the variability in the definition of stricture and successful dilatation and in the reporting of complications (per patient or per procedure). Finally, a recent review concluded that there were no significant differences between Savary bougies and balloon dilators for benign esophageal strictures in adults, but bougies were more cost effective since they were reusable. ${ }^{12}$

\section{Initiation and Frequency of Dilatations}

The scheduling and underlying philosophy of esophageal dilatation has been investigated. Some European centers, after advocating for routine postoperative dilatation/calibration, compared routine with selective dilatation, demonstrating less procedures and comparable rates of dysphagia or other complications when dilatations are performed only on symptomatic patients. ${ }^{72,73}$ The timing of first dilatation is less controversial, with most publications waiting at least 3 weeks after repair due to the increased risk of esophageal perforation. $^{70,74}$ Finally, there is insufficient evidence to support the ideal interval between dilatation sessions, with the published range between weekly and monthly, most using a shorter interval initially (every 2 weeks) and then spacing it out once

Table 4 Inflation pressure, success rate, and complications in selected series using balloon dilation

\begin{tabular}{|l|l|l|l|l|l|}
\hline Study, year & $N$ (total) & ATM & Success (\%) & Perforation (\%) & Surgery (\%) \\
\hline Lang et al $2001^{55}$ & $22(22)$ & $1.5-6$ & 100 & 9 & 0 \\
\hline Lan et al $2003^{119}$ & $63(77)$ & 10 & 97 & 1.5 & 3 \\
\hline Said et al $2003^{13}$ & $25(25)$ & 3 & 100 & 8 & 0 \\
\hline Ko et al $2006^{68}$ & $29(29)$ & Manual & 93 & 10 & 3 \\
\hline Alshammari et al $2011^{60}$ & $24(49)$ & 6 & $92^{\mathrm{b}}$ & $8^{\mathrm{b}}$ & $8^{\mathrm{b}}$ \\
\hline
\end{tabular}

Abbreviations: ATM, pressure (atmospheres); $N$, number of patients with esophageal atresia and total number treated in report.

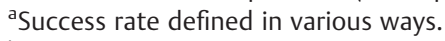

bsecifically for esophageal atresia patients. 
the area is not restricturing at the next session (- Table 5). 4,13,51,69,72

In summary, esophageal dilatation remains the mainstay of treatment for AS after EA repair. Current evidence appears to support the popularity of balloon dilatation over bougies, ${ }^{60}$ the latter remaining useful in certain circumstances and safe when used by experienced clinicians. ${ }^{62}$ The evidence also supports the investigation and treatment of strictures based on symptomatology as opposed to routine screening and dilatation.

\section{Medical Adjuncts to Dilatation}

\section{Steroids}

The use of steroid therapy as an adjunct to dilatation for esophageal stricture secondary to caustic ingestion in adults was described in 1967 by Knox et al, after several animal studies laid the groundwork for its use. ${ }^{75,76}$ It has now become a standard treatment modality for the treatment of corrosive esophageal stricture in adults. ${ }^{11,77}$ More recently, two randomized controlled trials have supported the use of steroid injection for the treatment of peptic strictures as well. ${ }^{78,79}$ Steroid injection generally results in a decreased need for further dilatation and/or an increased interval between dilatations. ${ }^{77-79}$ Holder et al reported steroid injection for pediatric esophageal strictures in 1969 and observed that longer strictures $(>1.5 \mathrm{~cm})$ were more likely to fail triamcinolone treatment. ${ }^{80}$ Gandhi et al provided the first evidence of durable patency after dilatation and steroid injection after EA repair, describing 12 patients treated with a mean of four injections. ${ }^{49}$ All 12 achieved symptomfree status, with a mean follow-up of 6 years. The most recent report of steroid injection for the treatment of esophageal stricture dates from 1995 and includes a single patient with EA out of seven treated with triamcinolone ${ }^{81}$; there are only scattered mentions of its use since then, even though other centers probably use it. ${ }^{14,82,83}$ More recent evidence supporting the use of steroid injection for pediatric esophageal stricture is lacking even though it is an established therapy in adults. ${ }^{11}$

Systemic steroid therapy in conjunction with esophageal dilatation has also been described as a maneuver before operative intervention for strictures refractory to local therapy, although this strategy has not been widely adopted and must be weighed against the adverse effects of systemic steroids. ${ }^{82,83}$ Furthermore, the potential for adrenal suppres- sion even after local steroid injection has been raised by previous publications, both in general and specifically during the treatment of AS after EA repair. ${ }^{84-86}$ We recommend that patients undergoing any treatment course of steroid injection undergo surveillance for adrenal suppression, with exogenous supplementation provided as required. In addition, intralesional steroids may have played a role in the spontaneous rupture of a right aortic arch by weakening the arterial wall adjacent to an AS in one of our EA patients. ${ }^{87}$

\section{Mitomycin C}

Mitomycin C (MMC) is a natural antitumor antibiotic that decreases the production of fibroblasts and scar tissue. Its topical use was originally described in the treatment of bladder tumors, ${ }^{88}$ and it took many years before its potential in the use of aerodigestive disease was realized. ${ }^{89}$ In 2006, two patients were described with ASs after EA repair refractory to conventional dilatation that responded to MMC application. ${ }^{90}$ A recent comprehensive review identified 7 out of the 31 patients who had ASs after EA repair treated with topical MMC administration. ${ }^{91}$ Considerable variability in the dose $(0.1-1.0 \mu \mathrm{g} / \mathrm{mL})$, the application regimen (1-12 applications) and the route of administration were encountered (retrograde or antegrade, with or without a protective sheath). Importantly, the publication identified no reported complications, and 27 out of the 31 patients had goodexcellent results albeit with a short follow-up. Fifty percent of the patients in the review by Berger et al derived from a single series by Rosseneu et al, which reported only a $50 \%$ success rate after 60 -month follow-up. ${ }^{92}$ This raises the possibility that MMC and dilatation may not produce durable results, although further investigations are required to clarify this point. A recent randomized trial has further supported the short-term efficacy of MMC in the treatment of recalcitrant strictures. This article demonstrated a clear reduction in the number of dilatations, as well as a higher rate of symptom resolution, albeit in strictures secondary to caustic ingestion. No complications were reported. ${ }^{93}$ The largest series to date describes 28 patients (18 after EA); MMC was considered successful as it decreased the number of subsequent dilatations and improved symptoms in 75 to $80 \%$ of patients. ${ }^{94}$ The only concern with MMC raised so far was a comment about gastric metaplasia being present at the AS site in two of the six patients within a few years of using MMC. ${ }^{95}$

In summary, while pharmacological adjuncts to dilatation have been popular for the treatment of AS, their evidence base

Table 5 Summary of recent literature evaluating the interval between dilatation sessions for the treatment of anastomotic stricture after esophageal atresia repair

\begin{tabular}{|l|l|l|l|}
\hline Study, year & $N$ (total) & Dilatation device & Interval between sessions \\
\hline Said et al $2003^{13}$ & $25(25)$ & Balloon & 1 week \\
\hline Bittencourt et al $2006^{51}$ & $54(125)$ & Bougie & 15 days \\
\hline Koivusalo et al $2009^{72}$ & $81(81)$ & Balloon & $1-3$ weeks \\
\hline Antoniou et al $2010^{69}$ & $59(59)$ & Balloon & 15 days \\
\hline
\end{tabular}

Abbreviation: $N$, number of patients with esophageal atresia and total number treated in report. 
remains relatively weak. Steroid injection has been established for a greater period of time, but both steroid injection and topical MMC application appear reasonable first-line adjuncts once dilatation has been deemed a failure.

\section{Procedural Adjuncts to Dilatation}

\section{Cauterization}

The use of endoscopic electrocautery in the treatment of esophageal stenosis was first reported by Brandimarte and Tursi in 2002, who described six adults that were safely and successfully treated. ${ }^{96}$ A randomized trial in adult ASs demonstrated equivalency with bougienage. ${ }^{97}$ Okada et al reported three cases of AS after EA repair that were successfully treated, although further details of the technique were not available in their publication. ${ }^{98}$ At this time, there is insufficient evidence to endorse endoscopic cauterization as a conventional treatment modality for AS after EA.

\section{Stenting}

The use of esophageal stenting has a long history in the prevention of stricture formation after caustic ingestion in adults and children, ${ }^{99}$ and has become a mainstay of care for obstructive esophageal cancer not amenable to resection. ${ }^{100}$ Its value in the treatment of severe stricturing disease has greatly increased the esophageal salvage rate; an Italian group has suggested that replacement only be considered after failure of stenting. ${ }^{101}$ In 2003, Broto et al reported 10 cases of pediatric esophageal stenosis that were successfully managed with a siliconated polypropylene stent, of which one patient had AS after EA repair. ${ }^{102}$ Covered retrievable expandable stents have also been reported for caustic strictures, although migration has been appreciated. ${ }^{103}$ A series of seven patients was recently reported, six of whom had a successful outcome after treatment with a tracheobronchial covered stent. Five of these patients had refractory AS after EA repair. ${ }^{104}$ Additional stent material has included biodegradable models (The SX-Ella Esophageal Degradable BD Stent; ELLA-CS, Hradec Kralove, Czech Republic), ${ }^{105}$ as well as urologic double "J" stents and more recently a custom dynamic stent. ${ }^{106,107}$ The custom dynamic stent is fashioned from a nasogastric tube covered with silicone drainage tubing until the desired thickness is achieved. In total, 79 patients have been treated with this stent over 12 years, 21 of whom were AS after EA repair. Indication for stent placement was failure to resolve after $>5$ dilatations. This group reported an $89 \%$ overall success rate, $81 \%$ in patients with AS secondary to EA. ${ }^{107}$
Several complications have been reported with the use of esophageal stenting in the pediatric population as a whole. Gagging after insertion is common but typically self-limited. Stent displacement occurs in approximately $15 \%$ of insertions, and usually results in displacement distal to the site of stricture. Migration of the stent into the stomach has also been rarely observed. ${ }^{104,107}$ More significantly, stent erosion has been reported as a cause of arterioesophageal fistulae. ${ }^{108}$ Thus, while esophageal stenting may obviate the need for an operative intervention for recalcitrant AS, it is not without risk. Cross-sectional imaging appears warranted to evaluate the proximity of great vessels (with or without possible aberrancy) and to minimize the risk of catastrophic exsanguination.

\section{Surgical Resection}

Although AS after EA repair continues to complicate the postoperative course of approximately one-third of all survivors, the number of reported patients who require resection of the stricture is remarkably small. - Table 6 highlights the number of patients that progress to operative stricture resection. Most patients treated with a second end-to-end anastomosis require postoperative dilatation again, and no patient has been reported that has failed stricture revision and gone on to require a second operative revision, although this is not always easy to tease out from large series of complicated patients. ${ }^{109}$ Stricturoplasty has been described for severe esophageal stenosis secondary to caustic ingestion, but has not been applied to patients after EA repair. ${ }^{110}$ Patch repair using a pedicled colonic graft has also been described. In a series of 15 patients reported by Othersen et al, two had developed AS after EA repair. Several significant complications were noted in the series (pseudodiverticulum formation, anastomotic leak, recurrent stricture), and this operation has not been widely adopted as a result. ${ }^{111}$ Interposition graft placement for the treatment of AS (as opposed to the treatment of long-gap EA) is exceedingly rare in the recent literature. Koivusalo et al describe one patient with AS treated with a pedicled jejunal flap. ${ }^{4}$ A recent review of jejunal interposition by Bax describes 19 patients undergoing the procedure-only one of which was performed to bridge a long stenosis. ${ }^{112}$ A recent large review $(n=97)$ of colonic replacement failed to identify any patients with an indication of refractory AS. ${ }^{113}$ Similarly, a multi-institutional review of gastric transposition failed to identify a single patient $(n=26)$ with the indication of stricture/stenosis. ${ }^{114}$ A larger series published by Spitz et al in 1987 identified 1 of the 32 EA

Table 6 Summary of literature evaluating stricture resection for anastomotic stricture after esophageal atresia repair

\begin{tabular}{|l|l|l|l|}
\hline Study, year & N (no. of type C) & Stricture N (\%) & Stricture resection (\%) \\
\hline Louhimo and Lindahl $1983^{53}$ & $273(\mathrm{~N} / \mathrm{A})$ & Not reported & $4(2)$ \\
\hline Okada et al $1997^{98}$ & $125(\mathrm{~N} / \mathrm{A})$ & $61(49)$ & $2(2)$ \\
\hline Mortell and Azizkhan $2009^{120}$ & $86(70)$ & $27(31)$ & $2(3)$ \\
\hline Koivusalo et al $2013^{4}$ & $130(110)$ & $102(78)$ & $7(7)$ \\
\hline
\end{tabular}

Abbreviations: $N$, number of survivors; $N / A$, not available. 


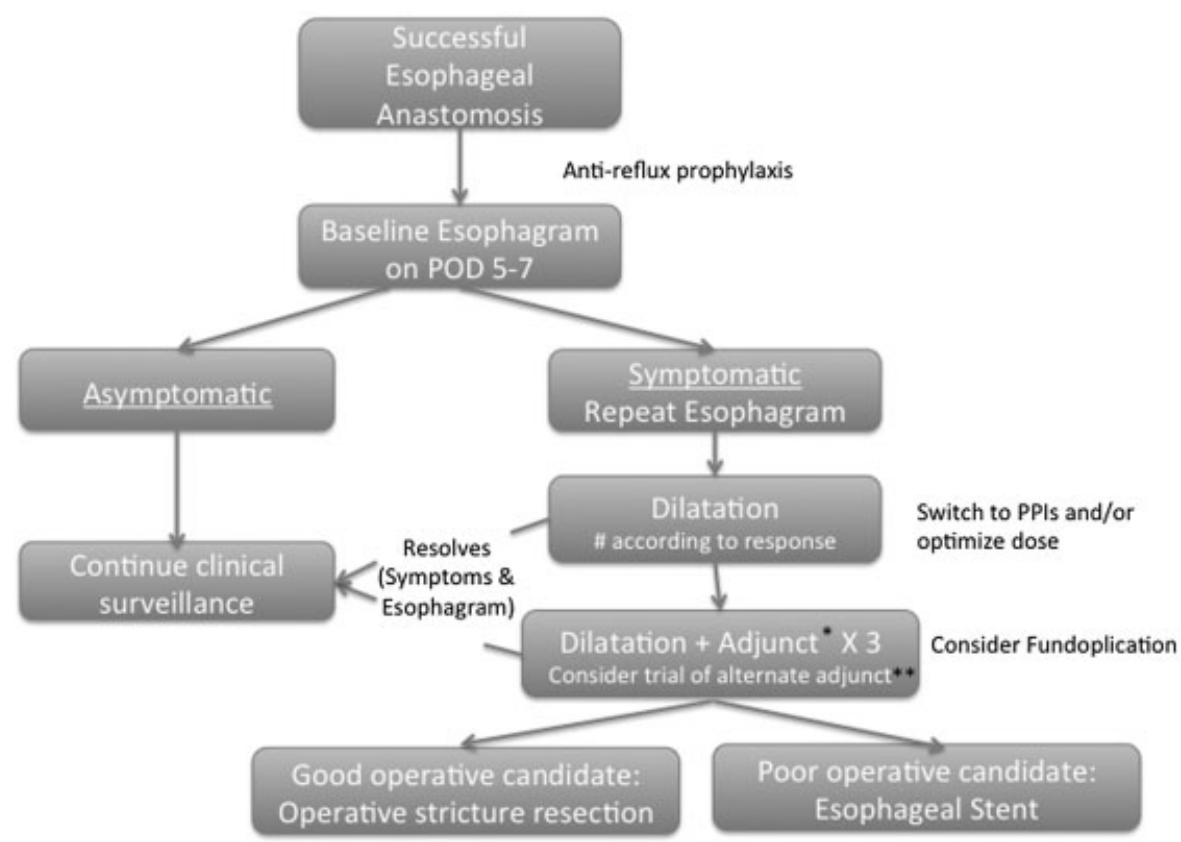

Fig. 1 Proposed algorithm for the management of esophageal anastomotic stricture. POD, postoperative day; PPI, proton pump inhibitor. ${ }^{*}$ Adjunct $=$ intralesional steroid or topical mitomycin $C .{ }^{* *}$ After three sessions of dilatation with one adjunct, consider using the alternative.

patients who required a gastric interposition because of an extensive stricture. ${ }^{115}$ Thus, interposition grafting appears to play an extremely limited role in the management of AS after EA. In the event that esophageal replacement is required, the choice of graft should be determined by individual and institutional expertise.

\section{Conclusion}

Although there has been a little improvement in the rate of the development of AS after EA repair, the armamentarium available for clinicians to treat this complication has continued to expand. Based on the available literature, the following algorithm is proposed by the authors (-Fig. 1). Patients presenting with dysphagia, feeding intolerance, or respiratory symptoms should be promptly investigated with a contrast esophagram. AS remains the most likely complication to explain the aforementioned symptomatology; however, uncontrolled reflux without stricture, recurrent or missed TEF, vocal cord paralysis, laryngeal cleft, tracheomalacia, or other rarer sequelae or associated malformation must be considered. Once AS is confirmed, endoscopic dilatation remains the primary treatment modality, with adjuncts reserved for patients who fail treatment after three to five sessions. The use of steroids or MMC has clearly reduced the need for operative stricture resection; at this time, both adjuncts appear equivalent in terms of efficacy and morbidity. Esophageal stenting remains an exciting new option in the treatment of AS that reduces the repeated anesthetic requirements associated with multiple dilatations. Obviating an invasive, reoperative surgical procedure must be tempered by the availability of local expertise and the risk of significant complications. Stricture resection also remains an important option in good operative candidates, with end-to-end anastomosis the reconstructive option of choice.

Most of the treatments available to prevent and treat stricture formation at the site of esophageal anastomosis remain poorly investigated with little evidence to inform their use. Complication rates have been inadequately characterized to date, and the outcome of unpublished patients continues to cloud the true efficacy and morbidity of dilatation, adjunctive therapies, and stenting. Comparative studies of competing treatment strategies are sorely lacking. Additional prospective evidence is required to continue to optimize strategies to prevent, investigate, and effectively manage patients with AS after EA.

\section{Conflict of Interest}

None

\section{References}

1 Haight C, Towsley HA. Congenital atresia of the esophagus with tracheoesphageal fistula: extrapleural ligation of fistula and endto-end anastomosis of esophageal segments. Surg Gynecol Obstet 1943;76:672-688

2 Engum SA, Grosfeld JL, West KW, Rescorla FJ, Scherer LR III. Analysis of morbidity and mortality in 227 cases of esophageal atresia and/or tracheoesophageal fistula over two decades. Arch Surg 1995;130(5):502-508, discussion 508-509

3 Alshehri A, Lo A, Baird R. An analysis of early nonmortality outcome prediction in esophageal atresia. J Pediatr Surg 2012;47(5):881-884

4 Koivusalo AI, Pakarinen MP, Rintala RJ. Modern outcomes of oesophageal atresia: single centre experience over the last twenty years. J Pediatr Surg 2013;48(2):297-303 
5 Laberge JM. Esophageal atresia and tracheo-esophageal fistula. In: Mattei P, ed. Fundamentals of Pediatric Surgery. New York: Springer; 2011:223-232

6 Hartnick CJ, Cotton RT. Congenital laryngeal anomalies. Laryngeal atresia, stenosis, webs, and clefts. Otolaryngol Clin North Am 2000;33(6):1293-1308

7 Mortellaro VE, Pettiford JN, St Peter SD, Fraser JD, Ho B, Wei J. Incidence, diagnosis, and outcomes of vocal fold immobility after esophageal atresia (EA) and/or tracheoesophageal fistula (TEF) repair. Eur J Pediatr Surg 2011;21(6): 386-388

8 Evans KL, Courteney-Harris R, Bailey CM, Evans JN, Parsons DS. Management of posterior laryngeal and laryngotracheoesophageal clefts. Arch Otolaryngol Head Neck Surg 1995;121 (12):1380-1385

9 Nambirajan L, Rintala RJ, Losty PD, Carty H, Lloyd DA. The value of early postoperative oesophagography following repair of oesophageal atresia. Pediatr Surg Int 1998;13(2-3):76-78

10 Kochman ML, McClave SA, Boyce HW. The refractory and the recurrent esophageal stricture: a definition. Gastrointest Endosc 2005;62(3):474-475

11 Kochhar R, Poornachandra KS. Intralesional steroid injection therapy in the management of resistant gastrointestinal strictures. World J Gastrointest Endosc 2010;2(2):61-68

12 Siersema PD, de Wijkerslooth LR. Dilation of refractory benign esophageal strictures. Gastrointest Endosc 2009;70(5): 1000-1012

13 Said M, Mekki M, Golli M, et al. Balloon dilatation of anastomotic strictures secondary to surgical repair of oesophageal atresia. $\mathrm{Br} \mathrm{J}$ Radiol 2003;76(901):26-31

14 Parolini F, Leva E, Morandi A, et al. Anastomotic strictures and endoscopic dilatations following esophageal atresia repair. Pediatr Surg Int 2013

15 Zhao R, Li K, Shen C, Zheng S. The outcome of conservative treatment for anastomotic leakage after surgical repair of esophageal atresia. J Pediatr Surg 2011;46(12):22742278

16 Borruto FA, Impellizzeri P, Montalto AS, et al. Thoracoscopy versus thoracotomy for esophageal atresia and tracheoesophageal fistula repair: review of the literature and meta-analysis. Eur J Pediatr Surg 2012;22(6):415-419

17 Oomen M. Systematic review of the literature: comparison of open and minimal access surgery (thoracoscopic repair) of esophageal atresia with tracheo-esophageal fistula (EA-TEF). In: Nazari S, ed. Front Lines of Thoracic Surgery. Rijeka, Croatia: In Tech; 2012:309-318

18 Pietsch JB, Stokes KB, Beardmore HE. Esophageal atresia with tracheoesophageal fistula: end-to-end versus end-to-side repair. J Pediatr Surg 1978;13( D(Suppl 0D):677-681

19 Touloukian RJ, Seashore JH. Thirty-five-year institutional experience with end-to-side repair for esophageal atresia. Arch Surg 2004;139(4):371-374, discussion 374

20 Poenaru D, Laberge JM, Neilson IR, Nguyen LT, Guttman FM. A more than 25-year experience with end-to-end versus end-toside repair for esophageal atresia. J Pediatr Surg 1991;26(4):472476, discussion 476-477

21 Myers NA. Oesophageal atresia: the epitome of modern surgery. Ann R Coll Surg Engl 1974;54(6):277-287

22 Holder TM, Cloud DT, Lewis JE Jr, Pilling GP IV. Esophageal atresia and tracheoesophageal fistula: a survey of its members by the surgical section of the American Academy of Pediatrics. Pediatrics 1964;34(4):542-549

23 Chittmittrapap S, Spitz L, Kiely EM, Brereton RJ. Anastomotic stricture following repair of esophageal atresia. J Pediatr Surg 1990;25(5):508-511

24 Chittmittrapap S, Spitz L, Kiely EM, Brereton RJ. Anastomotic leakage following surgery for esophageal atresia. J Pediatr Surg 1992;27(1):29-32
25 St. Peter SDV, Valusek PA, Snyder CL, Holcomb GW III, Ostlie DL. Impact of suture choice on stricture formation following repair of esophageal atresia. Ann Pediatr Surg 2007;3(2):75-79

26 Catalano P, Di Pace MR, Caruso AM, Salerno S, Cimador M, De Grazia E. A simple technique of oblique anastomosis can prevent stricture formation in primary repair of esophageal atresia. J Pediatr Surg 2012;47(9):1767-1771

27 Melek M, Cobanoglu U. A new technique in primary repair of congenital esophageal atresia preventing anastomotic stricture formation and describing the opening condition of blind pouch: plus (“+”) incision. Gastroenterol Res Pract 2011;2011:527323

28 Guo W, Fonkalsrud EW, Swaniker F, Kodner A. Relationship of esophageal anastomotic tension to the development of gastroesophageal reflux. J Pediatr Surg 1997;32(9):1337-1340

29 Nagaya M, Kato J, Niimi N, Tanaka S, Iio K. Proposal of a novel method to evaluate anastomotic tension in esophageal atresia with a distal tracheoesophageal fistula. Pediatr Surg Int 2005; 21(10):780-785

30 Khan KM, Foker JE. Use of high-resolution endoscopic ultrasonography to examine the effect of tension on the esophagus during primary repair of long-gap esophageal atresia. Pediatr Radiol 2007;37(1):41-45

31 McKinnon LJ, Kosloske AM. Prediction and prevention of anastomotic complications of esophageal atresia and tracheoesophageal fistula. J Pediatr Surg 1990;25(7):778-781

32 Castilloux J, Noble AJ, Faure C. Risk factors for short- and longterm morbidity in children with esophageal atresia. J Pediatr 2010;156(5):755-760

33 Bagolan P, Iacobelli Bd Bd, De Angelis P, et al. Long gap esophageal atresia and esophageal replacement: moving toward a separation? J Pediatr Surg 2004;39(7):1084-1090

34 Upadhyaya VD, Gangopadhyaya AN, Gupta DK, et al. Prognosis of congenital tracheoesophageal fistula with esophageal atresia on the basis of gap length. Pediatr Surg Int 2007;23(8):767-771

35 Brown AK, Tam PK. Measurement of gap length in esophageal atresia: a simple predictor of outcome. J Am Coll Surg 1996; 182(1):41-45

36 Ashcraft KW, Goodwin C, Amoury RA, Holder TM. Early recognition and aggressive treatment of gastroesophageal reflux following repair of esophageal atresia. J Pediatr Surg 1977;12(3): 317-321

37 Burge DM, Shah K, Spark P, et al; British Association of Paediatric Surgeons Congenital Anomalies Surveillance System (BAPSCASS). Contemporary management and outcomes for infants born with oesophageal atresia. Br J Surg 2013;100(4):515-521

38 Van Biervliet S, Van Winckel M, Robberecht E, Kerremans I. Highdose omeprazole in esophagitis with stenosis after surgical treatment of esophageal atresia. J Pediatr Surg 2001;36(9): 1416-1418

39 Hagander L, Muszynska C, Arnbjornsson E, Sandgren K. Prophylactic treatment with proton pump inhibitors in children operated on for oesophageal atresia. Eur J Pediatr Surg 2012;22(2): 139-142

40 Koivusalo A, Pakarinen MP, Rintala RJ. The cumulative incidence of significant gastrooesophageal reflux in patients with oesophageal atresia with a distal fistula-a systematic clinical, $\mathrm{pH}$-metric, and endoscopic follow-up study. J Pediatr Surg 2007;42(2): 370-374

41 Wheatley MJ, Coran AG, Wesley JR. Efficacy of the Nissen fundoplication in the management of gastroesophageal reflux following esophageal atresia repair. J Pediatr Surg 1993;28(1):53-55

42 Bergmeijer JH, Tibboel D, Hazebroek FW. Nissen fundoplication in the management of gastroesophageal reflux occurring after repair of esophageal atresia. J Pediatr Surg 2000;35(4):573-576

43 Holcomb GW III, Rothenberg SS, Bax KM, et al. Thoracoscopic repair of esophageal atresia and tracheoesophageal fistula: a multi-institutional analysis. Ann Surg 2005;242(3):422-428, discussion 428-430 
44 Snyder CL, Ramachandran V, Kennedy AP, Gittes GK, Ashcraft KW, Holder TM. Efficacy of partial wrap fundoplication for gastroesophageal reflux after repair of esophageal atresia. J Pediatr Surg 1997;32(7):1089-1091, discussion 1092

45 Esposito C, Langer JC, Schaarschmidt K, et al. Laparoscopic antireflux procedures in the management of gastroesophageal reflux following esophageal atresia repair. J Pediatr Gastroenterol Nutr 2005;40(3):349-351

46 Levin DN, Diamond IR, Langer JC. Complete vs partial fundoplication in children with esophageal atresia. J Pediatr Surg 2011; 46(5):854-858

47 Bolstad DS. The management of strictures of the esophagus. Ann Otol Rhinol Laryngol 1966;75(4):1019-1028

48 Karlan MS. Best treatment of esophageal stricture. N Engl J Med 1971;285(17):971

49 Gandhi RP, Cooper A, Barlow BA. Successful management of esophageal strictures without resection or replacement. J Pediatr Surg 1989;24(8):745-749, discussion 749-750

50 Orenstein SR, Whitington PF. Esophageal stricture dilatation in awake children. J Pediatr Gastroenterol Nutr 1985;4(4):557-562

51 Bittencourt PF, Carvalho SD, Ferreira AR, et al. Endoscopic dilatation of esophageal strictures in children and adolescents. J Pediatr (Rio J) 2006;82(2):127-131

52 Langston HT. The first successful total repair of congenital atresia of the esophagus with tracheoesophageal fistula. Ann Thorac Surg 1984;38(1):72-74

53 Louhimo I, Lindahl H. Esophageal atresia: primary results of 500 consecutively treated patients. J Pediatr Surg 1983;18(3): 217-229

54 Morrison LE. Experiences with dilatation of the esophagus following surgery for esophageal atresia. Ann Otol Rhinol Laryngol 1959;68(2):580-595

55 Lang T, Hümmer HP, Behrens R. Balloon dilation is preferable to bougienage in children with esophageal atresia. Endoscopy 2001;33(4):329-335

56 Jayakrishnan VK, Wilkinson AG. Treatment of oesophageal strictures in children: a comparison of fluoroscopically guided balloon dilatation with surgical bouginage. Pediatr Radiol 2001; 31(2):98-101

57 Batres LA, Liacouras C, Schnaufer L, Mascarenhas MR. Eosinophilic esophagitis associated with anastomotic strictures after esophageal atresia repair. J Pediatr Gastroenterol Nutr 2002;35(2): 224-226

58 Michaud L, Guimber D, Sfeir R, et al. [Anastomotic stenosis after surgical treatment of esophageal atresia: frequency, risk factors and effectiveness of esophageal dilatations]. Arch Pediatr 2001; 8(3):268-274

59 Serhal L, Gottrand F, Sfeir R, et al. Anastomotic stricture after surgical repair of esophageal atresia: frequency, risk factors, and efficacy of esophageal bougie dilatations. J Pediatr Surg 2010; 45(7):1459-1462

60 Alshammari J, Quesnel S, Pierrot S, Couloigner V. Endoscopic balloon dilatation of esophageal strictures in children. Int J Pediatr Otorhinolaryngol 2011;75(11):1376-1379

61 Lakhdar-Idrissi M, Khabbache K, Hida M. Esophageal endoscopic dilations. J Pediatr Gastroenterol Nutr 2012;54(6):744-747

62 Poddar U, Thapa BR. Benign esophageal strictures in infants and children: results of Savary-Gilliard bougie dilation in 107 Indian children. Gastrointest Endosc 2001;54(4):480-484

63 Christopoulos-Geroulanos G. Experience with esophageal dilatations in children. Ann Gastroenterology. 2003;16(2): 151-154

64 Hernandez LV, Jacobson JW, Harris MS. Comparison among the perforation rates of Maloney, balloon, and savary dilation of esophageal strictures. Gastrointest Endosc 2000;51(4 Pt 1):460-462

65 Stringel G, Lawrence C, McBride W. Repair of long gap esophageal atresia without anastomosis. J Pediatr Surg 2010;45(5): 872-875
66 Ball WS, Strife JL, Rosenkrantz J, Towbin RB, Noseworthy J. Esophageal strictures in children. Treatment by balloon dilatation. Radiology 1984;150(1):263-264

67 Hoffer FA, Winter HS, Fellows KE, Folkman J. The treatment of post-operative and peptic esophageal strictures after esophageal atresia repair. A program including dilatation with balloon catheters. Pediatr Radiol 1987;17(6):454-458

68 Ko HK, Shin JH, Song HY, et al. Balloon dilation of anastomotic strictures secondary to surgical repair of esophageal atresia in a pediatric population: long-term results. J Vasc Interv Radiol 2006;17(8):1327-1333

69 Antoniou D, Soutis M, Christopoulos-Geroulanos G. Anastomotic strictures following esophageal atresia repair: a 20-year experience with endoscopic balloon dilatation. J Pediatr Gastroenterol Nutr 2010;51(4):464-467

70 Kim I-O, Yeon KM, Kim WS, Park KW, Kim JH, Han MC. Perforation complicating balloon dilation of esophageal strictures in infants and children. Radiology 1993;189(3):741-744

71 Shemesh E, Czerniak A. Comparison between Savary-Gilliard and balloon dilatation of benign esophageal strictures. World J Surg 1990;14(4):518-521, discussion 521-522

72 Koivusalo A, Pakarinen MP, Rintala RJ. Anastomotic dilatation after repair of esophageal atresia with distal fistula. Comparison of results after routine versus selective dilatation. Dis Esophagus 2009;22(2):190-194

73 Koivusalo A, Turunen P, Rintala RJ, van der Zee DC, Lindahl H, Bax NM. Is routine dilatation after repair of esophageal atresia with distal fistula better than dilatation when symptoms arise? Comparison of results of two European pediatric surgical centers. J Pediatr Surg 2004;39(11): $1643-1647$

74 Laín A, Cerdá J, Cañizo A, et al. [Analysis of esophageal strictures secondary to surgical correction of esophageal atresia]. Cir Pediatr 2007;20(4):203-208

75 Knox WG, Scott JR, Zintel HA, Guthrie R, McCabe RE. Bouginage and steroids used singly or in combination in experimental corrosive esophagitis. Ann Surg 1967;166(6):930-941

76 Ashcraft KW, Holder TM. The expeimental treatment of esophageal strictures by intralesional steroid injections. J Thorac Cardiovasc Surg 1969;58(5):685-691, passim

77 Kochhar R, Makharia GK. Usefulness of intralesional triamcinolone in treatment of benign esophageal strictures. Gastrointest Endosc 2002;56(6):829-834

78 Ramage JI Jr, Rumalla A, Baron TH, et al. A prospective, randomized, double-blind, placebo-controlled trial of endoscopic steroid injection therapy for recalcitrant esophageal peptic strictures. Am J Gastroenterol 2005;100(11):2419-2425

79 Altintas E, Kacar S, Tunc B, et al. Intralesional steroid injection in benign esophageal strictures resistant to bougie dilation. J Gastroenterol Hepatol 2004;19(12):1388-1391

80 Holder TM, Ashcraft KW, Leape L. The treatment of patients with esophageal strictures by local steroid injections. J Pediatr Surg 1969;4(6):646-653

81 Zein NN, Greseth JM, Perrault J. Endoscopic intralesional steroid injections in the management of refractory esophageal strictures. Gastrointest Endosc 1995;41(6):596-598

82 Morikawa N, Honna T, Kuroda T, et al. High dose intravenous methylprednisolone resolves esophageal stricture resistant to balloon dilatation with intralesional injection of dexamethasone. Pediatr Surg Int 2008;24(10):1161-1164

83 Hishiki T, Kouchi K, Saito T, et al. Successful treatment of severe refractory anastomotic stricture in an infant after esophageal atresia repair by endoscopic balloon dilation combined with systemic administration of dexamethasone. Pediatr Surg Int 2009;25(6):531-533

84 Curtis JA, Cormode E, Laski B, Toole J, Howard N. Endocrine complications of topical and intralesional corticosteroid therapy. Arch Dis Child 1982;57(3):204-207 
85 Lilly JR, Bensard D. Intralesional steroid injection in the management of esophageal stricture. J Pediatr Surg 1989;24(12):1312

86 Lévesque DL, Baird R, Laberge J. Refractory strictures post-esophageal atresia repair: what are the alternatives? Dis Esophagus 2013;26. In press

87 Delisle M, Laberge J, Baird R. Aortic arch or descending aorta position during the repair of esophageal atresia? Time to take sides. Dis Esophagus 2013;26: In press

88 Mishina T, Oda K, Murata S, Ooe H, Mori Y. Mitomycin C bladder instillation therapy for bladder tumors. J Urol 1975;114(2): 217-219

89 Rahbar R, Jones DT, Nuss RC, et al. The role of mitomycin in the prevention and treatment of scar formation in the pediatric aerodigestive tract: friend or foe? Arch Otolaryngol Head Neck Surg 2002;128(4):401-406

90 Uhlen S, Fayoux P, Vachin F, et al. Mitomycin C: an alternative conservative treatment for refractory esophageal stricture in children? Endoscopy 2006;38(4):404-407

91 Berger M, Ure B, Lacher M. Mitomycin C in the therapy of recurrent esophageal strictures: hype or hope? Eur J Pediatr Surg 2012;22(2):109-116

92 Rosseneu S, Afzal N, Yerushalmi B, et al. Topical application of mitomycin-C in oesophageal strictures. J Pediatr Gastroenterol Nutr 2007;44(3):336-341

93 El-Asmar K, Amir M, Abdelkader H, El-Safoury H, Hamza A. Mitomycin $C$ application in resistant caustic esophageal stricture. Ann Pediatr Surg 2011;7(2):49-54

94 Bridenne M, Chapuy L, Gottrand F, et al. Efficacy and safety of the local application of Mitomycin C to recurrent esophageal strictures in children. Dis Esophagus 2013;26. In press

95 Michaud L, Gottrand F. Anastomotic strictures: conservative treatment.J Pediatr Gastroenterol Nutr 2011;52(Suppl (Suppl 1):S18-S19

96 Brandimarte G, Tursi A. Endoscopic treatment of benign anastomotic esophageal stenosis with electrocautery. Endoscopy 2002;34(5):399-401

97 Hordijk ML, van Hooft JE, Hansen BE, Fockens P, Kuipers EJ. A randomized comparison of electrocautery incision with Savary bougienage for relief of anastomotic gastroesophageal strictures. Gastrointest Endosc 2009;70(5):849-855

98 Okada A, Usui N, Inoue M, et al. Esophageal atresia in Osaka: a review of 39 years' experience. J Pediatr Surg 1997;32(11):1570-1574

99 Hill JL, Norberg HP, Smith MD, Young JA, Reyes HM. Clinical technique and success of the esophageal stent to prevent corrosive strictures. J Pediatr Surg 1976;11(3):443-450

100 Dubecz A, Watson TJ, Raymond DP, et al. Esophageal stenting for malignant and benign disease: 133 cases on a thoracic surgical service. Ann Thorac Surg 2011;92(6):2028-2032, discussion 2032-2033

101 De Peppo F, Zaccara A, Dall'Oglio L, et al. Stenting for caustic strictures: esophageal replacement replaced. J Pediatr Surg 1998;33(1):54-57

102 Broto J, Asensio M, Vernet JMG. Results of a new technique in the treatment of severe esophageal stenosis in children: poliflex stents. J Pediatr Gastroenterol Nutr 2003;37(2):203-206
103 Zhang C, Yu JM, Fan GP, et al. The use of a retrievable selfexpanding stent in treating childhood benign esophageal strictures. J Pediatr Surg 2005;40(3):501-504

104 Best C, Sudel B, Foker JE, Krosch TC, Dietz C, Khan KM. Esophageal stenting in children: indications, application, effectiveness, and complications. Gastrointest Endosc 2009;70(6):1248-1253

105 Vandenplas Y, Hauser B, Devreker T, Urbain D, Reynaert H, Quiros A. Endoscopic treatment of benign esophageal strictures with removable or biodegradable stents. In: Gershman G, Thomson M, eds. Practical Pediatric Gastrointestinal Endoscopy. 2nd ed. Oxford, UK: Wiley-Blackwell; 2011:156-164

106 Villalona GA, Sarhan M, Gandhi R. Novel technique for management of esophageal strictures: double "J" stents and the use of urologic dilators. Pediatr Surg Int 2010;26(3):331-333

107 Foschia F, De Angelis P, Torroni F, et al. Custom dynamic stent for esophageal strictures in children. J Pediatr Surg 2011;46(5): 848-853

108 Lo A, Baird R, De Angelis P, et al. Arterio-esophageal fistula after stenting for esophageal atresia. J Pediatr Gastroenterol Nutr 2013;56(5):e30-e31

109 Spitz L, Kiely E, Pierro A. Gastric transposition in children-a 21year experience. J Pediatr Surg 2004;39(3):276-281, discussion 276-281

110 Anderson KD, Acosta JM, Meyer MS, Sherman NJ. Application of the principles of myotomy and strictureplasty for treatment of esophageal strictures. J Pediatr Surg 2002;37(3):403-406

111 Othersen HB Jr, Parker EF, Chandler J, Smith CD, Tagge EP. Save the child's esophagus, Part II: Colic patch repair. J Pediatr Surg 1997;32(2):328-333

112 Bax KM. Jejunum for bridging long-gap esophageal atresia. Semin Pediatr Surg 2009;18(1):34-39

113 Hamza AF. Colonic replacement in cases of esophageal atresia. Semin Pediatr Surg 2009;18(1):40-43

114 Hirschl RB, Yardeni D, Oldham K, et al. Gastric transposition for esophageal replacement in children: experience with 41 consecutive cases with special emphasis on esophageal atresia. Ann Surg 2002;236(4):531-539, discussion 539-541

115 Spitz L, Kiely E, Brereton RJ. Esophageal atresia: five year experience with 148 cases. J Pediatr Surg 1987;22(2):103-108

116 Konkin DE, O'hali WA, Webber EM, Blair GK. Outcomes in esophageal atresia and tracheoesophageal fistula. J Pediatr Surg 2003;38(12):1726-1729

117 Rothenberg SS. Thoracoscopic repair of esophageal atresia and tracheo-esophageal fistula in neonates: evolution of a technique. J Laparoendosc Adv Surg Tech A 2012;22(2):195-199

118 Huang J, Tao J, Chen K, et al. Thoracoscopic repair of oesophageal atresia: experience of 33 patients from two tertiary referral centres. J Pediatr Surg 2012;47(12):2224-2227

119 Lan LC, Wong KK, Lin SC, et al. Endoscopic balloon dilatation of esophageal strictures in infants and children: 17 years' experience and a literature review. J Pediatr Surg 2003;38(12):1712-1715

120 Mortell AE, Azizkhan RG. Esophageal atresia repair with thoracotomy: the Cincinnati contemporary experience. Semin Pediatr Surg 2009;18(1):12-19 